in water, and for this reason its antibacterial activity was not examined by us in vitro. Iodinated and chlorinated phenyl ethers of type II have have tuberculostatic activity in vitro. A closer study of the diploicin molecule was, therefore, considered desirable.

As every position in the benzene nuclei in I is occupied, the simplest method of rendering the molecule soluble is by opening the depside group into the molecule. When this change is brought about by the action of alcoholic potash, under mild conditions, an ester is formed. With aqueous alkali, however, a solution of the sodium salt of the acid is readily obtained. A neutral solution of this compound, III, inhibits completely the growth in vitro of $M$ ycobacterium smegmatis at a dilution of $1 / 70,000$ and Myco. tuberculosis at a dilution of $1 / 100,000$ for 42 days.<smiles>CO[C@H]1[CH][C@H](C)[C@H](O)[C@H]1C(=O)O</smiles>

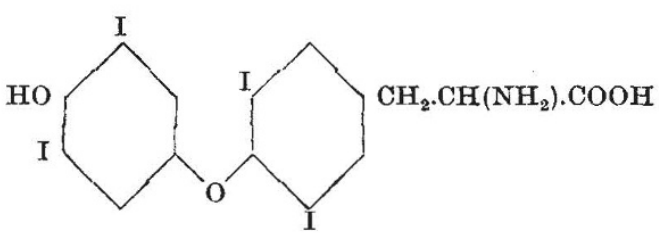

(V)

The carboxyl group in III is very unstable and in the presence of alkali readily loses carbon dioxide, forming a decarboxylated compound, IV, which is very much less soluble. It has not, however, suffered any diminution in antibacterial power. It is of interest that both III and IV inhibit completely the growth in vitro of Corynebacterium diphtherioe (mitis) at a dilution of $1 / 100,000$.

The only known substance, of the halogenated diphenyl ether type, occurring normally in the animal body is thyroxine (V), and its resemblance to diploicin suggested to me that hyperactivity of the thyroid gland, resulting in excessive secretion of thyroxine, might provide a defence against the spread of tubercular infection in the animal body.

Subsequent examination of the literature has shown considerable Subsequent examination of the literature has shown considerable
evidence that tuberculosis rarely develops in association with hyperevidence that tuberculosis rarely develops in association with hyperculosis. It is also believed that hypothyroidism predisposes to tuberculosis.

The experimental fact which would serve as a connecting link between diploicin and thyroxine has not so far been found. Thyroxine does not appear to exert any effect on the growth in vitro of the tubercle bacillus. Neither has it been possible to show, so far, that oral administration of diploicin to guinea pigs produces any of the symptoms usually associated with hyperactivity of the thyroid gland. A limited animal protection experiment with diploicin is at the moment being carried out.

The amount of thyroxine in the animal body at any time is probably too small, in any event. to have a direct effect on the tubercle bacilli, and possibly the resistance to the spread of tubereular infection in hyperthyroid cases is due to an indirect action as, for example, the hyperplasia of lymphoid tissue which takes place. While admitting that the hypothesis may prove to be invalid, the coincidence is too striking to be passed over without thorough investigation.

I am grateful to the Medical Research Council of Ireland, which is flnancing this investigation, and to Dr. P. A. McNally, Trinity College, Dublin, who is carrying out the biological tests. Prof. J. Algar is at present engaged in completing the work of Nolan et al. on the structure of the diploicin molecule.

VINCENT C. BARRY

University College, Dublin.

${ }^{2}$ Nolan, Sci. Proc. Roy. Dub. Soc., 21, 67 (1935).

2 Spillane, Keane and Nolan, Sci. Proc. Roy. Dub. Soc., 21, 333 (1936) 3 Davidson, Keane and Nolan, Sci. Proc, Roy. Dub. Soc., 23, 151 (1943). 1416 (1945).

s Rich, "The Pathogenesis of Tuberculosis" (Thomas, Springfield, Illinois, 1944).

\section{An Anti-Tick Salve for Lambs}

THE salving or smearing of sheep in autumn was part of the normal routine on sheep-farms in Scotland during the latter half of the eighteenth century. For reasons of cost and the labour involved, this practice fell into disuse about 1860 , except in the County of Sutherland, and was regarded as of merely historical interest by 1900 . Although it is customary to regard this old practice as being devoid of any rational basis, such an assumption is incorrect, since it was generally recognized that, as well as receiving increased protection from adverse weather, salved sheep yielded heavier fleeces of washed wool than sheep whose fleeces had not been 'laid', when the animals
were herded under comparable conditions.
One of the main purposes of salving, however, was to combat external parasites; and, although the subject is controversial it may not be entirely fortuitous that complaints of losses from 'trembling' rise steadily during the years following the cessation of this ancient practice in sheep husbandry. It is now known that the sheep tick, Ixodes ricinus, is involved in the transmission of three fatal or highly debilitating diseases of sheep, namely, (i) trembling or louping-ill, (ii) tick-borne fever, and (iii) tick-pyæmia ; but whereas measures have been devised which give considerable protection to adult sheep against these diseases or their vector, no really

With the objective of remedying the defect, fleld trials were conducted this spring in west Perthshire, Argyll and Islay, using an anti-tick salve on lambs throughout the seasonal period of tiek aetivity-a period which closely coincides with the lambing season. In former times, the standard smear or salve consisted of a mixture of lard and wood-tar (applied to the skin after parting the wool at intervals of about two inches), but in the above trials the salves used were-
(a) dibutyl phthalate, 20 per cent; and $(b)$ dibutyl phthalate, 10 per cent plus D.D.T., 10 per cent; both chemicals being incorporated in a lanoline base. The salve was applied to the lambs on the regions of the body where ticks tend to congregate, namely, lower jaw, ears, belly, legs and particularly the axillæ and groin. Each lamb received
$2 \mathrm{oz}$, of salve within four days of birth, although experience indicates that $1.5 \mathrm{oz}$. is enough.

From the results of salving 160 lambs in heavily tick-infested districts, it was found that the lambs were given a very high degree of protection from ticks for one month, and considerable protection for an additional fortnight. An unexpected feature is that the two salves are almost equally effective. These salves are, therefore, valuable aids in protecting lambs from the direct and indirect effects of "tickbite', during the most critieal period of their lives ; and should greatly minimize the inordinate losses and unthriftiness among hill-lambs.

I take the opportunity of expressing my thanks to Dr. D. D. Pratt of the Chemical Research Laboratory, Teddington, for his invaluable assistance, and also to the agricultural organisers in the respective counties for their enthusiastic co-operation.

West of Scotland Agricultural College,

D. STEWART MACLAGAN

$$
\text { Glasgow }
$$

\section{An Agent Delaying the Absorption of Penicillin}

THE rapid absorption and excretion of penicillin necessitates frequent injections at short intervals. Polyvinyl alcohol and a beeswax-peanut oil mixture have been suggested as agents causing slow release of injected penicillin. The successful use of the beeswax-peanut oil mixture, and a number of reports in the literature, seem to point to the advantage of suspended dry penicillin in a water-free base. The beeswax-peanut oil mixture has the disadvantage that the insect wax is foreign to the mammalian body. In the preparation described below, a highly purified fat, extracted from normal mammalian depot fat, is used in a certain mixture with peanut oil. In this way the portion which has the higher melting point is not foreign to the body.

Peanut oil has a
with in the body.

Depot fat from oxen was carefully freed from connective tissue, blood, etc., flnely cut and extracted with acetone in a Soxhlet apparatus. The extract was dried under reduced pressure. The dried material was then extracted with ether in a Soxhlet, the extract dried with anhydrous sodium sulphate and the ether removed under reduced pressure. The melting point was adjusted to $35-36^{\circ}$ by addition of peanut oil. The preparation was sterilized and further dried in a dry oven $\left(45\right.$ min., $\left.160^{\circ}\right)$. This altered the melting point but little. Finely powdered penicillin was suspended evenly throughout the molten mixture at $37^{\circ}$, approximately 50,000 units $/ \mathrm{ml}$. For injection the preparation was melted again in a water bath. Controls received the same amount of penicillin in an aqueous solution.

Owing to a fortunate hysteresis, the once molten mixture solidifled much below its melting point. The needle only needed slight warming, and injection was easy by means of a syringe which was not warmed beforehand. The molten mixture passed easily through needles of a size often used for injections in $\operatorname{man}(8 / 10 \mathrm{~mm}$.).

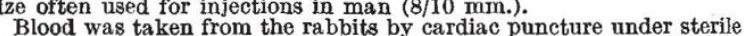
Blood was taken from the rabbits by cardiac puncture under sterile
conditions, at intervals after the injection. Typical results (penicillin conditions, at intervals after the injection. Typical
units/ml. serum) are shown in the following table.

\begin{tabular}{|c|c|c|c|c|}
\hline $\begin{array}{l}\text { Hours after sub- } \\
\text { cutaneous injection } \\
(45,000 \text { units })\end{array}$ & 3 & 4 & 6 & 8 \\
\hline $\begin{array}{l}\text { Control } \\
\text { Slow release prep. } \\
\text { No. } 3 \\
\text { Slow release prep. } \\
\text { No. } 3 \\
\text { Slow release prep. } \\
\text { No. } 4\end{array}$ & $\begin{array}{l}1 \cdot 06 \\
1 \cdot 06\end{array}$ & $<0.03$ & $\begin{array}{r}<0.03 \\
0.26 \\
0.26\end{array}$ & $\begin{array}{r}<0.03 \\
0.06 \\
>0.03 \\
0.26\end{array}$ \\
\hline
\end{tabular}

In no case was a local irritation, or indeed any marked reaction, seen on the site of the injection, at various intervals after it. Fourteen days after injection of $2.5 \mathrm{ml}$. into one rat, only small round and oval particles with smooth surfaces were found locally. To the naked eye these appeared very much like normal depot fat. Sections stained with Ehrlich's hæmatoxylin and Sudan IV showed no trace of local
inflammation or any pathological reaction around the numerous inflammation or any pathological reaction around the numerous were of normal appearance.

We are greatly indebted to Dr. A. P. Peeney of the Department of Bacteriology, Queen Elizabeth Hospital, for having determined the 